\title{
Modelling Servicescapes for Generational Satisfaction: The case of Five-Star hotels in Kenya
}

\author{
Okari, Yussuf Motari, Dr. Tom Mboya \\ $\mathrm{PhD}$ Student, School of Business and Economics, Kisii University, \\ Lecturer, School of Business and Economics, Kisii University, Kenya. \\ DOI: 10.29322/IJSRP.11.09.2021.p11760 \\ http://dx.doi.org/10.29322/IJSRP.11.09.2021.p11760
}

\begin{abstract}
This research investigated the effect of servicescapes on generational satisfaction outcomes among five-star hotels in Kenya. The study focused its attention on 23 five-star hotels where a sample of 289 delegates were identified for the study. Responses of Generation Y, X, baby boomers and the silent generations were taken into account. Three attributes associated with servicescapes including ambiance, layout and artefacts were considered. Primary data was collected by means of a structured questionnaire. Statistical Analysis of the research data used simple linear regression analysis with the significance in accordance with the output of SPSS 25.0. Findings indicated that ambiance, Layout and artefacts influenced generational satisfaction outcomes. Furthermore, the relationship between servicescapes and generational satisfaction outcomes was positive and significant. However, the contributory role of servicescapes to the satisfaction of the generational cohorts of delegates was barely 10 percent, notwithstanding its widespread application among five-star hotels in Kenya. On the basis of this results, the study recommends that managers of five-star hotels should reconsider the appropriateness or otherwise use servicescapes parsimoniously. On future research, the study recommends focus on expanding the scope of methodology to incorporate both quantitative and qualitative approaches, examination of the perception of customers and service providers concurrently, and a comparative study on the consumption behaviour of the Baby Boomers, the Silent generation, generation $\mathrm{X}$ and generation $\mathrm{Y}$ guests in the five-star hotels in Kenya.
\end{abstract}

Index Terms- servicescapes, Ambiance, Layout, artefact, generational Satisfaction

\section{INTRODUCTION}

$\mathrm{T}$ The use of servicescapes remain widespread among five star hotels in Kenya and across the world. Unlike other classification of hotels, these hotels are defined at its simplest as the kind of environment that surrounds the provision of services (Bitner, 1992). Bitner's approach classifies servicescapes into three main components including: ambiance, layout and artefacts. The deployment of servicescapes in five-star hotels is meant create guest satisfaction and in the end encourage them to make referral and become service patrons.

Therefore, five-star hotels spend significant amounts of resources to enhance their hotels spaces. These underpins the significant capital investment required to set up five star hotels globally. In most cases, these luxury brands compete to set up attractive hotel spaces. Therefore, Boru (2018) observes there is a disproportionate representation of the local brands among these premier class of hotels in Kenya. The international brands therefore dominated the Kenyan market with Rosa Kempinski, Dusit D2, and Intercontinental hotel being notable brands. Nevertheless, as of 2019, the hotel and its allied sectors contributed an average of $8.8 \%$ to Kenya's Gross Domestic Product (GDP). In the year, over 2 million visitors came to the country, with $13.5 \%$ of visitors citing business as their main purpose of travel to Kenya (Kenya National Bureau of Statistics, 2020).

On the basis of these enormous interest and funds spent on servicescapes, the explication of its role in generational satisfaction, growth and competitiveness is arguably one of the notable trends of marketing research. Furthermore, servicescapes is expected to contribute significantly to generational satisfaction. In practice, however, these hotels strive to position their services to meet the needs of the diverse generations of guests including generation $\mathrm{Y}, \mathrm{X}$, baby boomers and the silent generation. However, Dipietro (2020) notes that hotels continue to experience difficulty in defining the servicescapes requirement for each generational cohort.

According to Bitner (1992) satisfaction is achieved when hotel services meet or surpass guest's expectations. As a critical indicator of competitiveness, satisfaction is increasingly gaining traction among players in the sector. Although, there is concurrence that satisfaction bring significant economic benefits to hotel businesses, there is a growing concern that degrees of satisfaction differ across consumer segments. This means that consumers respond to goods and services differently (Taylor Jr. \& DiPietro, 2018). As opposed to satisfaction, the concept of generational satisfaction is recent in marketing literature. This concept relates the inherent perceptions of the cohorts in relation to their socialization. Therefore, Travis (2018) noted that, generations of guests form unique consumption behaviour towards services as they grow. These implies that they are expected to respond to servicescapes differently.

Generational satisfaction is therefore embodied in outcomes such as repeat visit, referral and patronage. The realization of the expected outcomes places the five-star hotels at a vantage point to gain competitiveness and growth. Neverthess, as alluded to earlier, the diverse cohorts of guests respond to servicescapes differently and as such the satisfaction outcomes are subsequently expected to vary among them. Therefore, the current study modelled the 
role of servicescapes on generational satisfaction outcomes among five-star hotels in Kenya. This was done using a quantitative approach in which case the hypothesis that:

Hypothesis: There is no statistically significant effect of servicescapes on generational satisfaction outcomes in five-star hotels in Kenya was tested with the aim of establishing the perceptions espoused by generation Y, X, baby boomers and the silent generation using regression analysis. Data was collected from delegates of corporate organizations who frequently visit the five star hotels for business purposes.

\section{LITERATURE REVIEW}

The study organized literature into distinct sections of theory and empirical studies related to servicescapes and generational satisfaction outcomes. In this case the theory of buyer behavior and relevant studies associated with the study constructs were reviewed.

\subsection{Theory of Buyer Behaviour}

The study was anchored on the Theory of Buyer Behaviour (TBB). This theory was proposed by Howard and Sheth in 1969 to explain the rationale behind the choice of goods and services by consumers. They argue that product choice is not a random but a systematic process with marketing, social and psychological influences. In particular, marketing influences such as servicescapes governs choice of services and ultimately levels of satisfaction. Given variance in attitudes and perceptions among generational cohorts, interpretation and subsequent response servicescapes differ significantly among segments.

While Howard and Sheth attempted to develop a generalizable theory, three main assumptions limit its application. First, generations of guests are assumed to undertake a rational and systematic process in selecting the five-star hotels. The study also assumed that individual delegates participated in choosing the five-star hotels. As such, the theory was adopted to examine the role played by servicescapes as stimulus for generational satisfaction, despites the fact that its development suffers from weak imperial and mathematical methods and the inability of the delegates to follow the entire model routines in the choice of hotels.

\section{Empirical literature}

The unique features that underpin the use of servicescapes primarily constitutes the tangible aspects of hotel services. In particular, servicescapes extends to attributes such as architectural design, ambience, layout and artefacts as advocated by Bitner (1992). The semiotic qualities of these spaces is meant to shape perceptions of guests and increase their likelihood of satisfaction. Likewise, these attributes position the hotels at a vantage point to create referral and patronage (Kamau, 2017). Besides, hotels are expected to narrow their focus on the specific needs and desires of their generations of guests as advised by Li and Zhang (2018).

Nevertheless, a large collection of literature, depicts customers as a homogeneous group with uniform needs that can be addressed with standardized services and goods, an aspect that negates the diverse needs that belong to the segments of customers. In this vain, Zwanka and Buff (2021) observes that the success of the five-star hotel is a matter predicated upon delivery of services designed to meet the unique needs of the demographics. This situation forces hotels to consider how customer segments process services-related information and subsequently act, to inform their marketing decisions. Of these segments, demographics such as age, race, gender and class dominate hotel guests.

Many attempts have been made to understand how customers respond when presented with ambiance. The interest of research was however skewed with most studies treating customers as a homogenous group (i.e., Pecotić, Bazdan, and Samardžija,2014; Kwong,2017; and Obinwanne,2019), on the contrary, the success of the hotel sector depends largely on operators understanding of demographic trends of its consumers as mentioned by Scott Taylor Jr. and DiPietro (2017). Thus, focus on whether ambiance appeals to the diverse demographics offers hotels prospects of growth and satisfaction. To this point, the study reviewed empirical literature on the aforementioned generations of guests.

Empirical literature attempts to relate servicescapes attributes to satisfaction with limited approach given to generational satisfaction in hotels. Olson and Park (2019), for instance, explored the relationship between ambiance and customer satisfaction in Korea. The study sought to develop an ambiancesatisfaction model tailored for the public service using Structural Equation Model (SEM). A random sample of 594 beneficiaries of public services in Seoul was selected and requested to answer questions related to ambiance, layout, and comfort. Findings indicated that ambiance significantly affected citizen satisfaction. Nevertheless, the study addressed ambiance - citizen satisfaction without considering the perceived role of age in the relationship.

Likewise, Pecotić, Bazdan, and Samardžija (2014) sought to link ambiance to the satisfaction of restaurant customers in Croatia. Attention was paid to gender and ambiance drivers such as sound, light, comfort among others. Questions were asked to 106 conveniently sampled restaurant customers, upon which, a significantly moderated relationship between ambiance and satisfaction was established. From the study, it was observed that perceptions of guests on ambiance were affected by gender. Nevertheless, aspects related to age of guests were not covered in the study.

Scott Taylor Jr. and DiPietro (2017) also sought to examine the effect of ambiance on satisfaction differences between generations of customers in the United States of America. Data was collected from 398 conveniently sampled baby boomers, generation $\mathrm{X}$ and $\mathrm{Y}$ restaurant guests. These guests were asked to answer questions regarding the design of the restaurant atmosphere. To compare the perception and satisfaction level across generations, Analysis of Variance (ANOVA) was utilized. Arising from this analysis, a significant difference between satisfaction of baby boomers, generation $\mathrm{X}$ and $\mathrm{Y}$ guests with respect to ambiance items was realized.

Similarly, limited studies have been conducted on the relationship between layout and artefacts and generational satisfaction outcomes. Attempts to establish its role to satisfaction remain prevalent Bogicevic, Bujisic, Cobanoglu, and Feinstein (2018) for example, addressed the role of this construct on satisfaction of generation of guests in the United States of America. In a quasi-experimental research design, 762 students conveniently sampled from selected universities, were requested to compare these attributes of hotels. Data collected on these attributes was then computed using analysis of variance 
(ANOVA). A profound influence of age was observed on the relationship between hotel layout on guest satisfaction. A disparity in perception of this attributes was noted with baby boomers being indifferent to the role of hotel layout and artefacts, while their generation $\mathrm{Y}$ counterparts were greatly influenced by these attributes.

Hendriyani (2018) examined the role of layout on satisfaction guests in Indonesia. A convenience sample of 105 guests was identified from 22 selected restaurants to which a questionnaire was administered. Qualitative data was collected from an interview conducted on the hotel managers. The qualitative data was summarised into themes while quantitative data was analysed using factor analysis. The findings of the study indicated that layout significantly influences guest satisfaction.

Kwong (2017) sought to investigate the role of artefacts on satisfaction of Chinese customers. Being conscious of the fact that, majority of the customers now belong to generation Y, customers between the ages of 20-25 years were targeted in the study. The outcome of a Principal Component Analysis (CPA) modelled response indicated that these attributes had a positive relationship with satisfaction. However, the contributory role of these attributes to satisfaction was minimal.

Harjit (2018) conducted a descriptive study on the relationship between artefacts on satisfaction of generation $\mathrm{X}$ and $\mathrm{Y}$ customers in Kenya. The study focused on graduate and undergraduate students between the ages of 18 and 50 years. A proportionally stratified sample of 311 and 81 undergraduate and graduate students were selected by simple random sampling respectively. Chi-square was used to compare responses between the two groups of students and to establish the relationship between the endogenous factor. The outcome of this analysis revealed a significant relationship between the endogenous factors. Although responses were expected to vary with age, no significant differences between generation $\mathrm{X}$ and $\mathrm{Y}$ was reported.

\section{RESEARCH AND METHODOLOGY}

This study employed correlational research design to examine the relationship between servicescapes and generational satisfaction outcomes, Roger and Boru (2018). A census of the 23 five-star hotels spread across the Nairobi, Coastal, South Rift and Mt. Kenya regions was undertaken. Out of these a target population of 500 managers of 34 corporate organizations with service contract with the five-star hotels in Kenya was purposively identified. Of these managers, Directors, Coordinators and the Heads of Administrative units formed the unit of analysis.

From the aforementioned target population, a sample of 289 was arrived at using Yamane (1969) formula as shown:

$$
n=\frac{N}{1+N e^{2}}
$$

Thus:

$$
n=\frac{500}{1+500\left(0.05^{2}\right)}
$$

$\mathrm{n}=222$ respondents

To ensure adequate data collection, the study sought to provide for non-response as some abstention was expected in the study. To remedy this, a non-response rate of $30 \%$ was provided in line with the recommendations by Fosnacht, Sarraf, Howe, and Peck (2017). This non-response was computed as shown:

$$
n=\left(\frac{30}{100} \times 222\right)+222=289
$$

Subsequently, a structured questionnaire was used to collect data from the respondents. The instrument was tested to ascertain reliability and validity before the actual data collection process was undertaken. To test for validity, confirmatory factor analysis was conducted on $10 \%$ (29 respondents) of the sample where items related to servicescapes demonstrated a good fit model (Chisquare $=7.009 ; \mathrm{KMO}=0.677 ; \mathrm{p}=0.000 ; \mathrm{KMO}>0.6$ ). Using the Cronbach alpha formula;

$$
\alpha=\frac{N \cdot C o v}{\operatorname{Var}+(N-1) \cdot C o v}
$$

the test of reliability was also undertaken. Results indicated that the instrument was reliable with servicescapes items meeting the set criteria $(\alpha=0.751 ; \alpha>0.7)$.

Data was then collected between January and April 2021 from the identified organizations after obtaining the required research documentation. The research instrument contained demographic characteristics of respondents and structured questions constituting of 5-point Likert scales with each having three sub-items and 12 questions. All responses were received by the month of April 2021 and the data was immediately cleaned in readiness for analysis. The data collected was then entered into Statistical Package for Social Sciences (SPSS) code book and analysed using regression analysis. The model of data analysis in this research is as follows:

$\mathrm{GSO}=\beta 0+\beta 1 \mathrm{SS}+\varepsilon$

$\begin{array}{ll}\text { GSO } & =\text { Generational satisfaction outcomes } \\ \beta 0 & =\text { Constant } \\ \beta 1 & =\text { Coefficient } \\ \varepsilon & =\text { Error term }\end{array}$

\section{RESUlt AND DisCUSSION}

\section{Test for Normality}

To effectively conduct a regression, basic assumptions of multiple regressions were examined. The test for normality assumption Kolmogorov-Smirnov and Shapiro-Wilk tests were used. This method tests the deviation of the data from the normal distribution as depicted in Table 1.

Table 1: Normality Test

Kolmogorov-Smirnova

This publication is licensed under Creative Commons Attribution CC BY

http://dx.doi.org/10.29322/IJSRP.11.09.2021.p117XX
Shapiro-Wilk 


\begin{tabular}{lllllll} 
& Statistic & Df & Sig. & Statistic & Df & Sig. \\
\hline Ambiance & .107 & 250 & .000 & .977 & 250 & .000 \\
Layout and artefacts & .068 & 250 & .007 & .985 & 250 & .012 \\
Generational Satisfaction & .073 & 250 & .003 & .991 & 250 & .113
\end{tabular}

According to the decision criteria, a p-value greater than 0.05 is not significant(Field, 2009) indicative of a distribution within a sample that is not significantly different from a normal distribution (i.e., it is probably normal). On the other hand, when the $\mathrm{p}$ value is less than 0.05 the distribution is significantly different from that of the normal distribution. With ( $\mathrm{p}<.05)$ across; servicescapes attributes and generational satisfaction outcomes, the results in Table 1 show that the results were significant even after transformation, indicative of a normally distributed data.

\section{Multicollinearity Tests}

Multicollinearity test was done through Variance Inflation Factor (VIF) approach. Results in Table 2 indicate that VIF for ambiance was 1.464 and that of layout and artefacts stood at 1.449.

Table 2: Multicollinearity Test

\begin{tabular}{|c|c|c|}
\hline Model Coefficients & $\begin{array}{l}\text { Collinearity } \\
\text { Statistics }\end{array}$ & \\
\hline & Tolerance & VIF \\
\hline Ambiance & .683 & 1.464 \\
\hline $\begin{array}{l}\text { Layout } \\
\text { Artefacts }\end{array}$ & .741 & 1.349 \\
\hline
\end{tabular}

The results depicted in table 2 indicate that all the servicescapes constructs had a VIF of less than 10 and tolerance of more than 0.1 ruling out multicollinearity problem. Otherwise, Bryman (2012) argues that a VIF of above 10 indicates a Multicollinearity problem.

\section{Test for Homoscedasticity} below :

To predict homoscedasticity a scatter plat was used as shown

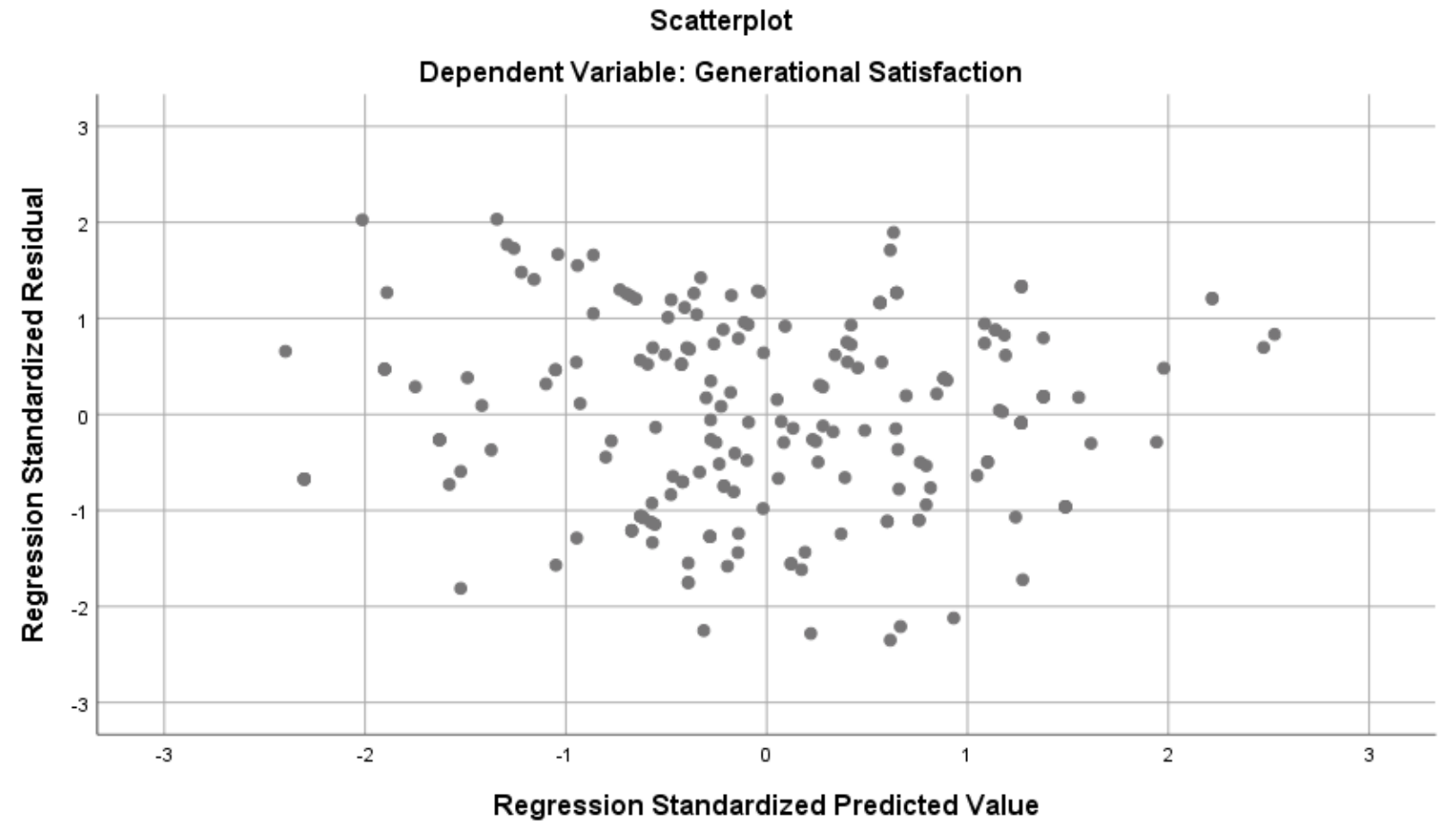

Figure 1: Heteroscedasticity test.

Figure 1 show that the residuals are equally distributed in the scatter plot, therefore, the data collected represents a homoscedastic distribution. This means that the assumption of homoscedasticity was fully met by the data collected.

\subsection{Descriptive Statistics}

This publication is licensed under Creative Commons Attribution CC BY.
The study established the effect of servicescapes on generational satisfaction outcomes. In doing so, the study described the role of hotel ambiance, layout, and artefacts using measures of central tendency as shown in table 3. The study observed that servicescapes influenced generational satisfaction outcomes with a mean of 4.0383 and standard deviation of 0.7676 , the role of each attribute however appear to vary as shown. 
Table 3: Servicescapes Generations Satisfaction Outcomes

\begin{tabular}{|c|c|c|c|c|c|c|}
\hline Variable & Item & $\mathbf{N}$ & Mean & $\begin{array}{l}\text { Std. } \\
\text { Deviation }\end{array}$ & Sk & Ku \\
\hline \multirow[t]{5}{*}{ Ambiance } & Hotel interior and exterior are well lit & 251 & 4.04 & .728 & -.493 & .204 \\
\hline & $\begin{array}{l}\text { The color schemes and decorations make the hote } \\
\text { attractive }\end{array}$ & $\mathrm{e} 251$ & 4.08 & .719 & -.386 & -.193 \\
\hline & Background music is entertaining to guests & 251 & 4.13 & .780 & -.737 & .351 \\
\hline & $\begin{array}{l}\text { Hotel room temperature provides comfort to } \\
\text { guests }\end{array}$ & 0251 & 3.94 & .919 & -.761 & .174 \\
\hline & Mean for Ambiance & & 4.0475 & 0.7865 & -0.59425 & 0.134 \\
\hline \multirow[t]{6}{*}{$\begin{array}{l}\text { Layout } \\
\text { artefacts }\end{array}$} & $\begin{array}{l}\text { andThe collection of artefacts displayed at the hote } \\
\text { is attractive to guests }\end{array}$ & el251 & 4.03 & .794 & -.491 & .018 \\
\hline & The hotel furniture is sufficient and comfortable & 251 & 4.24 & 668 & -.642 & .667 \\
\hline & The hotel layout is spacious & 251 & 4.31 & .726 & -1.247 & 2.575 \\
\hline & Hotel artefacts are informative to guests & 251 & 4.03 & .794 & -.491 & .018 \\
\hline & Mean for Layout and Artefacts & 251 & 4.152 & 0.745 & -0.717 & 0.819 \\
\hline & General mean & & 4.0997 & 0.76575 & -0.6556 & 0.4765 \\
\hline
\end{tabular}

According to the findings, ambiance was observed to be a strong predictor of generational satisfaction among the five-star hotels. This was seen by the mean response of 4.0475 and the corresponding standard deviation of 0.7865 . Interestingly, music formed the strongest predictor, with hotel room temperature being the least. Taking into consideration the findings, the hotels should enhance the use of temperature within the hotels to promote guest satisfaction. These attributes, therefore, encourage generations of delegates to either revisit, refer or patronise the hotels. These results, are congruent to the cross-sectional study by Adzoyi (2015) and a descriptive study by Harjit (2018) who affirmed the role of ambiance on generational satisfaction. The findings, however contradict those of Scott Taylor Jr. and DiPietro (2017), who found that ambiance has little or no impact on guest satisfaction. The findings of the current study, therefore, support the use of ambiance as a viable means of guest satisfaction.

Layout and artefacts were also seen to influence generational satisfaction outcomes among the five-star hotels. This is evidenced by a mean response of 4.152 and standard deviation of 0.745 . Furthermore, a spacious layout as well as furniture and comfort were identified as the strongest predictors of satisfaction(Mean>4.2). These results, however, contradicts the quantitative findings of Bogicevic, Bujisic, Cobanoglu, and Feinstein (2018) who noted that guests were indifferent to the use of these approaches in the luxury hotels. This leaves the hotels with an option of aligning the layout and artefacts with the needs of the generations of delegates.

Using the measures of central tendency, the study explored the nature of distribution of the scores. The skewness and kurtosis of the servicescapes items, therefore, revealed that the Ku values were leptokurtic in distribution as none of the items showed scores greater than 10(in absolute value). Similarly, Sk values were generally below 3 (in absolute value). This observations, therefore, show that there was no severe deviation from the normal distribution, which would prevent the use of linear regression or hierarchical regression analysis.

Furthermore, to test the study hypothesis, simple linear regression was used. Table 4 presents the corresponding regression weights and standard error of estimates.

Table 4: Model Summary for Servicescapes and Generational Satisfaction Outcomes

\begin{tabular}{lllll} 
Model & R & R Square & Adjusted R Square & Std. Error of the Estimate \\
\hline 1 & $.321 \mathrm{a}$ & .103 & .099 & .52852
\end{tabular}

The coefficient of determination ( $R 2=0.103)$ shown in Table 4.19 indicates that servicescapes accounted for $10.3 \%$ of the satisfaction of the identified generations of delegates (Gen. Y, X, baby boomers, silent generation) in five-star hotels in Kenya, leaving $89.7 \%$ to be accounted by exogenous factors. Likewise, the servicescapes -generational satisfaction outcomes were seen to be weak but positive as portrayed by the correlation coefficient $(\mathrm{R}=.321)$.

To test the goodness of fit of the regression model, ANOVA was adopted. The results are displayed in table 5.

Table 5: ANOVA Test for Servicescapes and Generational Satisfaction Outcomes 


\begin{tabular}{lllllll} 
Model & & Sum of Squares & Df & Mean Square & F & Sig. \\
\hline 1 & Regression & 7.991 & 1 & 7.991 & 28.608 & $.000 \mathrm{~b}$ \\
& Residual & 69.554 & 249 & .279 & & \\
& Total & 77.545 & 250 & & & \\
\hline
\end{tabular}

The regression output $(\mathrm{F}=28.608 ; \mathrm{df}=1 ; \mathrm{sig}=.000<0.05)$ shows that the model was a suitable fit to predict generational satisfaction outcomes. It is interpretable therefore, that items used to measure servicescapes were able to explain the variation in generational satisfaction among five-star hotels in Kenya. The output belonging to this model, demonstrate a significant difference among means of servicescapes items postulated in the study. These results allowed the study to proceed with hypothesis testing.

The first hypothesis was tested by running simple linear regression. The acceptance or rejection criteria was based on $\mathrm{p}$ value where $p<0.05$ was accepted and vice versa. The results of this test are shown in table 6 .

Table 6: Coefficients for Servicescapes and Generational Satisfaction Outcomes

\begin{tabular}{|c|c|c|c|c|c|c|}
\hline \multirow[b]{2}{*}{ Model } & & \multicolumn{2}{|c|}{ Unstandardized Coefficients } & \multicolumn{2}{|c|}{$\begin{array}{l}\text { Standardized } \\
\text { Coefficients }\end{array}$} & \multirow[b]{2}{*}{ Sig. } \\
\hline & & B & Std. Error & Beta & $\mathrm{t}$ & \\
\hline 1 & (Constant) & 2.020 & .288 & & 7.025 & .000 \\
\hline & Servicescapes & .376 & .070 & .321 & 5.349 & .000 \\
\hline
\end{tabular}

The results $(\beta=2.020, t=5.349, p=0.000<0.05)$ imply that the relationship between servicescapes and generational satisfaction was significant. As a result, the null hypothesis was rejected and the alternate hypothesis supported. As such, the study concludes that the relationship among the constructs was both positive and significant for the young, middle -aged and senior generations of delegates in five-star hotels in Kenya. These findings are in line with those of Scott et al., (2017), who observed a significant relationship between servicescapes and generational satisfaction outcomes. But, Bogicevic et., al., (2018) refutes these findings by observing that there was no significant relationship between the constructs among guests in the United States of America. The model equation is therefore,

$$
\begin{array}{ll}
\mathrm{GSO} & =\beta 0+\beta 1 \mathrm{SS}+\varepsilon \\
\mathrm{GSO} & =2.020+0.376 \mathrm{SS}
\end{array}
$$

Where: GSO =Generational Satisfaction Outcomes

$$
\begin{array}{ll}
\text { SS } & =\text { Servicescapes } \\
\varepsilon & =\text { error term }
\end{array}
$$

\section{CONCLUSIONS AND MANAGERIAL ImPlicAtions}

Findings indicated that the contribution of servicescapes to the satisfaction of the generations of delegates was barely $10 \%\left(R^{2}=0.103\right)$ indicating that its contribution remains low and temporary. Therefore, the application of servicescapes is still elusive in the sector. These means that hotels, perhaps, have neither articulated nor properly matched the requirements of servicescapes to generations of guests.

On the basis of the findings, the study recommends as follows: i. A comparative investigation between local and internationally acclaimed five-star hotels on the application of servicescapes.

ii. A comparative study on the consumption behaviour of the Baby Boomers, the Silent generation, generation $\mathrm{X}$ and generation $\mathrm{Y}$ guests in the five-star hotels in Kenya.

The study however suffered a number of limitations, for instance, the questionnaire used in data collection was framed using Likert-scale items, described as an ordinal scale. There are concerns, however, that the use of ordinal scale exposes analysis to distorted estimates and incorrect chi-square and goodness-of-fit measures and standard errors as explained by Blalock (2017). Any violation of the scaling assumptions in the study could easily lead to serious biased results and conclusions. To mitigate this limitation, data collected was aggregated into composite scales for purposes of converting them into continuous data. This process allowed the use of measures of central tendency and regression analysis. Therefore, the study is limited from generalization.

\section{REFERENCES}

[1] Bitner, M. J. (1992). Servicescapes: The impact of physical surrounding on customer and employees. Journal of Marketing, 56(2), 57-71.

[2] Bogicevic, V., Bujisic, M., Cobanoglu, C., \& Feinstein, A. H. (2018). Gender and age preferences of hotel room design. International Journal of Contemporary Hospitality Management, 30(2), 874-899

[3] Bryman, A. (2012). Sampling in qualitative research. Social research methods. N.Y: Oxford University Press, 4, 415-429.

[4] Fosnacht, K., Sarraf, S., Howe, E., \& Peck, L. K. (2017). How important are high response rates for college surveys? The Review of Higher Education, 40(2), 245-265.

[5] Harjit, P. K. (2018). The Effect of Servicescape on Customer Satisfaction: A Study on USIU-A Library (unpublished Doctoral dissertation), United States International University-Africa, Nairobi. 
[6] Kamau. B. N. (2017). Influence of Servicescapes on customer satisfaction in restaurants within classified hotels in Nairobi County, Kenya (unpublished dissertation). Kenyatta University, Nairobi.

[7] Kwong, D. L. (2017). The role of servicescapes in Hotel Buffet Restaurant, Journal of Hotel and Business Management, 6(1),1-8.

[8] Lynch, P. (2017). Mundane welcome: Hospitality as life politics. Annals of Tourism Research, 64, 174-184.

[9] Government of Kenya, (2020). Kenya National Bureau of Statistics. Nairobi: Government Printer.

[10] Li, X., Jianmin, H., Hou, B., \& Zhang, P. (2018). Exploring the innovation modes and evolution of the cloud-based service using the activity theory on the basis of big data. Cluster Computing, 21(1), 907-922.

[11] Obinwanne, C. O. (2019). Interior design of hotel rooms as a factor affecting customer satisfaction in hotels, International Journal of Advanced Studies in Ecology, Development, and Sustainability,6(1), 34-45.

[12] Olson, E., \& Park, H. J. (2019). The impact of age on gay consumers' reaction to the physical and social servicescapes in gay bars, International Journal of Contemporary Hospitality Management, 31(9), 3683-3701.

[13] Pecotić, M., Bazdan, V., \& Samardžija, J. (2014). Interior design in restaurants as a factor influencing customer satisfaction, RIThink, 4, 10-14.

[14] Scott, T. Jr. \& Robin, B. D. (2017). Generational perception and satisfaction differences related to restaurant service environment. International Journal of Hospitality \& Tourism Administration, 9(4), 374-396.
[15] Taylor Jr, S., \& DiPietro, R. B. (2018). Generational perception and satisfaction differences related to restaurant service environment International Journal of Hospitality \& Tourism Administration, 19(4), 374396.

[16] YuSheng, K., \& Ibrahim, M. (2019). Service innovation, service delivery, and customer satisfaction and loyalty in the banking sector of Ghana, International Journal of Bank Marketing, 37(5),1215-1233.

[17] Zwanka, R. J., \& Buff, C. (2021). COVID-19 generation: A conceptual framework of the consumer behavioral shifts to Be caused by the COVID-19 pandemic. Journal of International Consumer Marketing, 33(1), 58-67.

\section{AUTHORS}

First Author - Okari, Yussuf Motari, ${ }^{*}$, PhD Student, School of Business and Economics, Kisii University, Kenya. E-mail:

ymotari@gmail.com

Second Author - Dr. Tom Mboya, Lecturer, School of Business and Economics, Kisii University, Kenya. E-mail:

tmboyagmail@.com 